\title{
ANALISIS HIDROLOGI UNTUK MENDAPATKAN DEBIT PUNCAK SUNGAI BENGKULU DENGANMENGGUNAKAN HIDROGRAFSATUANSINTETIK NAKAYASU
}

(Studi Kasus DAS Sungai Bengkulu)

\author{
Khairul Amri ${ }^{1)}$, Besperi ${ }^{2)}$, Chandra Aji Negara ${ }^{3)}$, \\ ${ }^{1,2)}$ Dosen Program StudiTeknikSipil, Fak. Teknik Universitas Bengkulu \\ ${ }^{3)}$ Mahasiswa Program StudiTeknikSipil, Fak. Teknik Universitas Bengkulu
}

\begin{abstract}
Abstrak
Tujuan penelitian ini adalah untuk mendapatkan debit puncak akibat intensitas curah hujan pada DASBengkulu dalam menganalisis hidrologi dengan menggunakan Hidograf Satuan Sintetik HSS Nakayasu .Berdasarkan hasil perhitungan distribusi frekuensi terhadap 3 metode curah hujan yaitu metode ditribusi Gumbel Tipe I, Log Pearson Tipe III dan Log Normal maka metode yang digunakan untuk perhitungan curah hujan rencana adalah Metode Gumbel Tipe I dengan periode ulang 2, 5, 10, 25, 50dan100tahun yaitu 90,350 mm, 201,556 mm, 275,173 mm, 368,217 mm, 437,233 mm dan 505,738 mm.Dari hasil analisis hidrologi diperoleh debit puncak pada DAS Bengkulu untuk periode ulang 100 tahun dengan metode HSS Nakayasu 7197,99 yaitu $\mathrm{m}^{3} /$ detik dengan waktu puncak sebesar 6 jam.
\end{abstract}

Kata kunci :Curah Hujan, periode Ulang, Hidrograf Satuan Sintetik, Debit Puncak.

\begin{abstract}
The purpose of this researchwas to obtain the peak discharge due to the intensity of rainfall in the Watershed of Bengkulu in analyzing the hydrology using Synthetic Unit Hydrograph(SUH) Gama I Method, SUH Nakayasu Method. Based on the result of the frequency distribution calculation of the three rainfall methods which are Distribution of Gumbel Type I Method, Log Pearson Type III Method and Log Normal Method, then the method used for rainfall design calculation is Distribution of Gumbel Type I method with return periods of 2, 5, 10, 25, 50 and 100years are 90,350 mm, 201,566 mm, 275,173 mm, $368,217 \mathrm{~mm}, 437,233 \mathrm{~mm}$ dan 505,738 mm.Fromthe result of hydrology analysis, thepeak discharge in Watershed of Bengkulu for a return period of 100 years by using SUH Nakayasu Method is $7197,99 \mathrm{~m}^{3} /$ second with the peaktime 6 hours.
\end{abstract}

Keywords: Rainfall, Return Period, Synthetic Unit Hydrograph, Peak Discharge. 


\section{PENDAHULUAN}

Kota Bengkulu terletak di bagian Utara Propinsi Bengkulu dengan koordinat geografis dari 5 $5^{\circ} 40^{\prime} 2^{\prime}$ ' Lintang Selatan sampai 10040'104', Bujur Timur. Kota ini berada di kawasan pesisir Pantai Barat Sumatera yang memiliki 8 Kecamatan terletak di Pesisir atau Tepi Laut. Daerah Kota Bengkulu terdapat sebuah sungai yang berhulu pada sisi barat bukit barisan dan mengalir ke Samudra Indonesia.

Daerah Aliran Sungai (DAS) adalah suatu wilayah daratan yang merupakan satu kesatuan dengan sungai dan anak-anak sungainya, yang berfungsi menampung, menyimpan dan mengalirkan air yang berasal dari curah hujan ke danau atau ke laut secara alami.

Daerah Aliran Sungai (DAS) merupakan salah satu sumberdaya alam berupa unit manajemen yang berfungsi sebagai penghasil barang dan jasa yang bermanfaat bagi kehidupan.

Daerah Sungai Bengkulu merupakan salah satu DAS yang dimiliki oleh Provinsi Bengkulu yang berada di wilayah teritorial Kota Bengkulu. Aliran sungai Bengkulu ini mengalir melewati 3 kecamatan dan 7 kelurahan di sepanjang aliran sungai.

Kawasan DAS Air Bengkulu mengairi sawah sekitar 650 Ha. Berada pada kelurahan pasar Bengkulu, Semarang, Surabaya danTanjung Jaya.Selama ini sawah pada kawasan DAS Air Bengkulu sering mengalami banjir yang di akibatkan oleh meluapnya sungai Bengkulu kurang berfungsinya bangunan air yang terdapat pada aliran sungai Bengkulu merupakan faktor yang mendukung banjir itu terjadi.
Jadi, perlu adanya penelitian tentang berapa debit sungai air Bengkulu menggunakan hidrografsatuan sintetik dalam beberapa periode tahunan sebagai masukan untuk perencanaan bangunan distribusi di DAS Air Bengkulu.

Debit puncak penting untuk diketahui dalam kerangka pengendalian banjir dan perancangan bangunan pengendali debit banjir (Rahim dalam Budiawan, 2012).Asdak (2014) mengatakan debit puncak dapat dikatakan sebagai debit kritis yang menyebabkan banjir Debit puncak terjadi ketika seluruh aliran permukaan yang berada di Daerah Aliran Sungai (DAS) mencapai titik outlet. Pendugaan debit puncak dengan metode hidograf digunakan untuk mengetahui debit puncak pada suatu DAS. Adapun model hidograf yang digunakan pada penelitian ini adalah model Hidrograf Satuan Sintetik (HSS) Nakayasu.

\section{TINJAUAN PUSTAKA}

\section{Siklus Hidrologi}

Siklus hidrologia adalah proses yang diawali oleh evaporasi/penguapan kemudian terjadinya kondensasi dari awan hasil evaporasi. Awan terus terproses, sehingga terjadi salju dan atau hujan yang jatuh kepermukaan tanah.Pada muka tanah air hujan ada yang mengalir di permukaan tanah, sebagian air run off dan sebagian infiltrasi /meresap kedalam lapisan tanah.Air run off mengalir di permukaan tanah kemudian kepermukaan air di sungai, danau, danl aut. Air infiltrasi meresap kedalam lapisan tanah dan akhirnya akan sampai di sungai, danau, danlaut. Kemudian terjadi lagi proses berikutnya (Hasmar, 2012). 


\section{Daerah Aliran Sungai (DAS)}

Daerah Aliran Sungai

(DAS) merupakan daerah yang di batasi punggungpunggung gunung dimana air hujan yang pada daerah tersebut akan di tampung oleh punggung gunung tersebut dan di alirkan melalui sungai sungai kecil kesungai utama. Daerah aliran sungai biasanya dibagi menjadi daerah hulu, tengah dan hilir (Asdak, 2007).

\section{Analisis Hidrologi}

Data hidrologi adalah kumpulan keterangan atau fakta mengenai fenomena hidrologi (hydrologic phenomena), seperti besarnya curah hujan, temperatur, penguapan, lama penyinaran matahari, kecepatan angin, debit sungai, tinggi muka air sungai, kecepatan aliran, konsentrasi sedimen sungai akan selalu berubah menurut waktu (Triatmodjo, 2008).

Amri K, (2014) bentuk dan panjang aliran sungai juga mempengaruhi kecepatan aliran pada titik tertentu pada bagian hulu menuju muara sungai (hilir) dan mempengaruhi besarnya debit puncak pada waku tertentu di suatu sungai.

\section{Analisis Curah Hujan}

Data curah hujan dan debit merupakan data yang paling mendasar dalam perencanaan/penelitian pembuatan bangunan air. Data curah hujan yang dipakai untuk perhitungan debit banjir rencana adalah hujan yang terjadi pada Daerah Aliran Sungai (DAS) pada waktu yang sama (Sosrodarsono dan Takeda, 1976).

\section{Analisis Frekuensi}

Analisis frekuensi bertujuan untuk mencari hubungan antara besarnya suatu kejadian ekstrim (maksimumdan minimum) dan frekuensinya berdasarkan distribusi probabilitas. Secara umum analisa frekuansi yang dihitung meliputi: parameter statistik, distribusi peluang kontinyu, dan uji kecocokan (Kamiana, 2011).

\section{Analisis Intensitas Curah Hujan}

Untuk menentukan Debit Banjir Rencana (Design Flood), perlu didapatkan harga suatu intensitas curah hujan terutama bila digunakan metode rasional. Intensitas curah hujan adalah ketinggian curah hujan yang terjadi pada suatu kurun waktu dimana air tersebut berkonsentrasi (Soemarto dalam Surono dan Nadeak, 2005).

\section{METODE PENELITIAN}

\section{Pengumpulan Data}

Proses pengumpulan data dilakukan dengan mencari data yang dibutuhkan untuk melakukan penelitian. Data yang digunakan adalah Data Primer dan Data Sekunder. Data Primer yang digunakan dalam penelitian ini yaitu :

\section{Luas Penampang}

Pengukuran luas penampang dilakukan langsung dilapangan sesuai dengan SNI 20882015 tentang Tata cara pengukuran debit aliran sungai dan saluran terbuka menggunakan alat ukur arus dan pelampung. Adapun alat yang digunakan dalam pengukuran adalah meteran dan bambu

2. Kecepatan Aliran

Pengukuran kecepatan aliran sesuai dengan SNI 20882015 tentang Tata 
cara pengukuran debit aliran sungai dan saluran terbuka menggunakan alat ukur arus dan pelampung. Pengukuran kecepatan aliran ini dapat dilakukan dengan menggunakan current meter atau pelampung.

3. Debit

Data debit aliran diperoleh dari hasil kecepatan aliran dikalikan dengan luas penampang.

Data sekunder yang digunakan dalam penelitian ini antara lain:

1. Peta DAS dan Peta topografi DAS Sungai Bengkulu didapatdari BWS Sumatera VII.

2. Data curah hujan selama 10 tahun terakhir (2008-2017) beserta stasiun hujan yang ada didalamnya didapat dari BMKG Provinsi Bengkulu.

\section{Alat Penelitian}

Peralatan yang digunakan pada penelitian ini diantaranya:

1. Alat tulis digunakan untuk mencatat hasil pengukuran.

2. Roll meter yang digunakan sebagai alat pengukur di lapangan.

3. Current meteryang digunakan untuk menghitung kecepatan aliran sungai.

4. peilschaal yang digunakan untuk menghitung kedalaman dalam penampang basah sungai.

5. Stopwatchdigunakan untuk mengukur lamanya waktu yang diperlukan.

6. Kalkulator digunakan perhitungan data.

7. Komputer digunakan untuk mengolah data.

\subsection{Pelaksanaan Penelitian}

Tahapan pelaksanaan penelitian yang akan dilakukan adalah sebagai berikut:

1. Perhitungan curah hujan harian maksimum rerata untuk tiap-tiap tahun data dengan metode Partial Series.

2. Menentukan parameter statistik dari data yang telah diurutkan dari kecil kebesar, yaitu Deviasi standar (Sd), Koefisien kemencengan (Cs), Koefisien Kurtosis $(\mathrm{Ck})$, dan Koefisien variasi $(\mathrm{Cv})$.

a. Hitung nilai rata-rata

$$
\overline{\mathrm{X}}=\frac{\sum_{\mathrm{i}=1}^{\mathrm{n}} \mathrm{Xi}}{\mathrm{n}}
$$

b. Hitung deviasi standar

$$
\mathrm{Sd}=\sqrt{\frac{\sum_{i=1}^{\mathrm{n}}\left(\mathrm{X}_{\mathrm{i}}-\overline{\mathrm{X}}\right)^{2}}{\mathrm{n}-1}}
$$

c. Hitung koefisien kemencengan

$$
C s=\frac{n \sum_{i=1}^{n}\left\{\left(X_{i}\right)-\bar{X}\right\}^{2}}{(n-1)(n-2) S d^{3}}
$$

d. Hitung koefisien kurtosis

$$
\mathrm{Ck}=\frac{\frac{1}{\mathrm{n}} \sum_{\mathrm{i}=1}^{\mathrm{n}}\left\{\left(\mathrm{X}_{\mathrm{i}}\right)-\overline{\mathrm{X}}\right\}^{4}}{\mathrm{Sd}^{4}}
$$

e. Hitung koefisien variasi

$$
\mathrm{Cv}=\frac{\mathrm{Sd}}{\overline{\mathrm{X}}}
$$

3. Analisis curah hujan rencana dicoba dengan menggunakan distribusi, yaitu distribusi Gumbel Tipe I, Log Pearson Tipe III, dan Log Normal. Rumus umum yang digunakan $\mathrm{X}_{\mathrm{t}}=\overline{\mathrm{X}}+\mathrm{Kt} \times \mathrm{S}$.

4. Uji kecocokan sebaran menggunakan Chi-Kuadrat dan Smirnov-Kolmogorov, dengan kriteria pengujian: 
Untuk Uji Chi-Kuadrat jika nilai $\mathrm{f}^{2}$

Hitungan $<\mathrm{F}^{2}$ cr (diterima).

Untuk Uji Smirnov-Kolmogorov jika

nilai Dmaks < Do kritis (diterima).

5. Penentuan waktu konsentrasi hujan Tc dengan rumus Kirpich.

$t_{c}=0,06628 \times L^{0,7 T} \times S^{-0,385}$

6. Analisis intensitas curah hujan dihubungkan dengan kejadian dan lamanya curah hujan, rumus yang digunakan adalah rumus Dr. Mononobe.

$\mathrm{I}_{\mathrm{t}}=\frac{\mathrm{R}_{24}}{\mathrm{t}_{\mathrm{c}}} \times\left[\frac{\mathrm{t}_{\mathrm{c}}}{\mathrm{t}}\right]^{2 / 3}$

7. Menganalisis debit aliran dasar (base flow) dengan melakukan perhitungan kerapatan jaringan sungai (D) terlebih dahulu, kemudian dimasukkan kedalam Rumus debit aliran dasar sebagai berikut:

$$
\begin{aligned}
& \mathrm{D}=\frac{\text { Panjang Total Tingkat Sungai }}{\text { Luas DAS (A) }} \\
& \mathrm{QB}=0,4751 \times \mathrm{A}^{0,6444} \times \mathrm{D}^{0,9430}
\end{aligned}
$$

8. Menentukan curah hujan efektif jamjaman.

9. Analisis Hidrograf Satuan dengan Metode Nakayasu.

Metode HSS Nakayasu:

Untuk $0<\mathrm{t}<\mathrm{T}_{\mathrm{p}}$ dengan rumus

$Q_{t}=Q_{p} \times\left[\frac{\mathrm{t}}{T_{p}}\right]^{2,4}$

Untuk $\mathrm{T}_{\mathrm{P}} \leq \mathrm{t} \leq \mathrm{T}_{\mathrm{P}}+\mathrm{T}_{0,3}$ dengan rumus $\mathrm{Q}_{\mathrm{t}}=\mathrm{Q}_{\mathrm{P}} \times 0,3^{\left(\mathrm{t}-\mathrm{T}_{\mathrm{p}}\right) \mathrm{T}_{0,3}}$

Untuk $_{\mathrm{P}}+\mathrm{T}_{0,3} \leq \mathrm{t} \leq \mathrm{T}_{\mathrm{P}}+\mathrm{T}_{0,3}+1,5 \mathrm{~T}_{0,3}$ dengan rumus $\mathrm{Q}_{\mathrm{t}}=\mathrm{Q}_{\mathrm{p}} \times 0,3^{\left[\left(\mathrm{t}-\mathrm{T}_{\mathrm{p}}\right)+\left(0,5 \mathrm{~T}_{0,3}\right)\right]\left(\mathrm{T}_{0,3}\right)}$

Untuk $\mathrm{t}>\mathrm{T}_{\mathrm{P}}+\mathrm{T}_{0,3}+1,5 \mathrm{~T}_{0,3}$ dengan rumus $\mathrm{Q}_{\mathrm{t}}=\mathrm{Q}_{\mathrm{P}} \times 0,3^{\left.\left[\mathrm{t}-\mathrm{T}_{\mathrm{P}}\right)+\left(1,5 \mathrm{~T}_{0,2}\right)\right]\left(2 \mathrm{~T}_{0,3}\right)}$
10. Analisis debit banjir rencana dengan menggunakan MetodeHSS Nakayasu. Metode HSS Nakayasu

$$
: Q_{p}=\frac{A \times R_{o}}{3,6 \times\left(0,3 \times T_{p}+T_{0,3}\right)}
$$

11. Menentukan besarnya debit puncak $\left(Q_{p}\right)$ dengan periode ulang $5,10,25,50$ dan 100.

Rekapitulasi Hasil Perhitungan Debit

Rencana

\begin{tabular}{|c|c|}
\hline \multirow{2}{*}{$\begin{array}{c}\text { Periode } \\
\text { Ulang }\end{array}$} & Debit Banjir Rencana (m3/detik) \\
\cline { 2 - 2 } & HSS Nakayasu \\
\hline 2 & 64,456 \\
\hline 5 & 239,901 \\
\hline 10 & 356,044 \\
\hline 25 & 502,837 \\
\hline 50 & 611,721 \\
\hline 100 & 719,799 \\
\hline
\end{tabular}

Dari Tabel 4.28 Berdasarkan hasil perhitungan dan pertimbangan keamanan, efisiensi serta ketidakpastian besarnya debit banjir yang terjadi di daerah tersebut, maka metode yang dipakai debit puncak yaitu dengan metode HSS Nakayasu dengan periode ulang 100 tahun. Dinyatakan bahwa periode ulang100 tahun dengan debit puncak $7197,99 \mathrm{~m}^{3} /$ detik.pada DAS Bengkulu dapat dijadikan sebagai bahan dasar untuk perencanaan bangunan Bendung, dimana suatu perencanaan bangunan tanggul atau tubuh bendung mampu menampung dan mengendalikan debit puncak yang akan terjadi pada bangunan tersebut.

\section{KESIMPULAN}

Berdasarkan hasil pembahasan maka penulis dapat menarik kesimpulan sebagai berikut:

1. Debit puncak yang didapat pada DAS Bengkulu untuk periode ulang 100 tahun 
dengan metode HSS Nakasayu yaitu $719,799 \mathrm{~m}^{3} /$ detik dengan waktu puncak sebesar 6 jam.

2. Hujan rancangan didapat dengan berbagai periode ulang 2, 5, 10, 25, 50 dan100 berturut-turut adalah sebesar 90,350 mm; 201,556 mm; 275,173 mm; $368,217 \mathrm{~mm} ; 437,233 \mathrm{~mm}$ dan 505,738 mm. Data curah hujan pada DAS Bengkulu menunjukkan pola distribusi curah hujan dengan pemilihan jenis sebaran dan jenis sebaran adalah Metode Gumbel Tipe I .

\section{SARAN}

1. Diperlukan stasiun hujan yang lebih banyak dan merata untuk DASBengkulu dengan luasan cukup besar .

2. Data curah hujan yang digunakan disarankan sebaiknya lebih banyak, karena semakin panjang tahun data yang digunakan akan menghasilkan kemencengan yang lebih kecil terhadap perhitungan.

\section{DAFTAR PUSTAKA}

Amri, K., 2014. Analisis debit puncak DAS padang guci Kabupaten Bengkulu Selatan.

Asdak, C., 2014. Hidrologi dan PengelolaanDaerah Aliran Sungai,
Gajah Mada University Press, Yogyakarta.

BP-DAS Bengkulu, 2017.Naskah Rencana Pengelolaan DAS Bengkulu buku II, Bengkulu.

Budiawan, S. S., 2012. Pendugaan Debit Puncak Menggunakan Model Rasional danSCS-CN (Soil Conservation Service-Curve Number), Fakultas Kehutanan IPB, Bogor.

Hasmar, H. H. (2012). Drainasi Terapan. Yogyakarta: UII Press Yogyakarta.

Kamiana, I. M., 2010. Teknik Perhitungan Debit Rencana Bangunan Air, Graha Ilmu, Yogyakarta.

Sosrodarsono, Ir. S., dan Takeda, K., 1976. Hidrologi Untuk Pengairan, PT. Pradnya Paramita, Jakarta.

Surono., dan Nadeak, T. H., 2005. Evaluasi Waduk dan Perencanaan Bendugan Ketro Kabupaten Seragen Propinsi Jawa Tengah, Fakultas Teknik UNDIP, Semarang.

Triatmodjo, B., 2008. Hidrologi Terapan, Beta Offset, Yogyakarta. 